\title{
INTERNET E EDUCAÇÃO: UMA ANÁLISE
}

\author{
Clarissa Peres Fontana ${ }^{1}$
}

RESUMO: Utilizando a metodologia da pesquisa bibliográfica este artigo analisa o uso da internet na educação por meio do aplicativo de mensagens WhatsApp. A evolução das tecnologias relacionadas a comunicação, e as próprias redes de comunicação, permitem a troca de mensagens de forma instantânea e aproxima realidades permitindo diferentes usos. Um destes usos é na educação, no contexto da atual pandemia do novo coronavírus. Situações como a atual emergência sanitária ou como o desastre ambiental ocorrido no Líbano em 2019 impulsionaram o uso das redes sociais e aplicativos de comunicação em diferentes formas. No caso do Líbano, um desastre ambiental impediu as aulas presenciais fazendo com que as escolas e educadores buscassem alternativas para continuar com as aulas de forma remota. No caso da pandemia do novo coronavírus, novas alternativas pedagógicas foram buscadas para também continuar o ensino remoto. Neste sentido, explorar estas formas na educação pode ser oportuno ao processo pedagógico. Entretanto, este uso das tecnologias na escola e nas salas de aula deve ser mediado pelo objetivo educacional. A tecnologia que apresenta recursos de entretenimento também oferece subsídios para o processo de ensino-aprendizagem. A experiência do Líbano com o WhatsApp, analisada neste artigo, revela os processos necessários para o uso pedagógico como o conhecimento do aplicativo, adaptação e o necessário acompanhamento por parte dos educadores. No fim deste artigo também há uma reflexão sobre o uso da tecnologia na realidade social dos alunos e das escolas, bem como as suas limitações e deficiências. Outrossim, a tecnologia se apresenta como uma ferramenta pedagógica para a escola contemporânea em situações de crise ou não.

Palavras-chave: Celular. Tecnologia. Pandemia. Educação.

ABSTRACT: Using the methodology of bibliographic research, this article analyzes the use of the internet in education through the WhatsApp messaging application. The evolution of technologies related to communication, and the communication networks themselves, allow the exchange of messages instantly and bring realities closer together, allowing for different uses. One of these uses is in education, within the context of the current pandemic of the new coronavirus. Situations such as the current health emergency or the environmental disaster that occurred in Lebanon in 2019 have boosted the use of social networks and communication applications in different ways. In the case of Lebanon, an

\footnotetext{
I Licenciada em Pedagogia e pós-graduada em Educação Especial pela Faculdade de Carapicuíba. E-mail: clarissa.fontana@hotmail.com.
} 
environmental disaster prevented in-person classes, causing schools and educators to look for alternatives to continue classes remotely. In the case of the new coronavirus pandemic, new pedagogical alternatives were sought to also continue remote teaching. In this sense, exploring these forms in education can be opportune to the pedagogical process. However, this use of technologies in school and classrooms must be mediated by the educational objective. Technology that features entertainment features also provides subsidies for the teaching-learning process. Lebanon's experience with WhatsApp, analyzed in this article, reveals the necessary processes for pedagogical use, such as knowledge of the application, adaptation and the necessary follow-up by educators. At the end of this article there is also a reflection on the use of technology within the social reality of students and schools, as well as its limitations and deficiencies. Furthermore, technology presents itself as a pedagogical tool for contemporary schools in situations of crisis or not.

Keywords: Cell. Technology. Pandemic. Education.

\section{INTRODUÇÃO}

Desde a descoberta do fogo, o desenvolvimento da humanidade tem andado lado a lado com a evolução da tecnologia, numa grande corrida em ritmo lento, que atravessou milênios, e de que se pode dizer que a humanidade levou ligeira vantagem, a maior parte do tempo.

Isso até o século XX, quando houve uma explosão tecnológica inédita, cujos efeitos aceleraram-se exponencialmente, desde a II Guerra Mundial, em que tiveram lugar as primeiras descobertas importantes em eletrônica, e as primeiras experiências em programação, mesmo antes da existência do primeiro computador, que o transístor logo possibilitaria.

A segunda metade do século XX apenas tornou o processo mais veloz: na década de I970, os computadores tornaram-se uma realidade palpável, e em 198I surgiram os primeiros computadores pessoais. Comprovava-se, assim, a Lei de Moore, que o presidente da Intel, Gordon Earle Moore, formulara em 1965: a cada dois anos, a capacidade dos computadores dobraria. A humanidade começava a perder a corrida para a tecnologia.

Nem o mais desvairado autor de ficção científica, porém, teria previsto o inacreditável fenômeno que é a internet. O que era apenas uma rede criada para permitir, em caso de guerra, a troca de informações entre membros geograficamente distantes do governo americano, começou, em 1969, a tornar-se o que conhecemos hoje: naquele ano, o 
primeiro e-mail foi trocado entre duas universidades americanas. A comunicação nunca mais seria a mesma.

Essa transformação foi tão impactante que é fácil esquecer que a internet tem outro mérito notável: abrigar praticamente toda a bagagem do conhecimento humano de todos os tempos, e disponibilizá-lo a qualquer um com acesso à internet.

Este acesso foi grandemente facilitado pelo advento do smartphone, por volta do ano 200o, e mais especialmente, pela chegada do Iphone e pela invenção do sistema operacional Android, em 2007, circunstâncias que puseram literalmente na palma da mão do ser humano comum todo aquele (informação) poder nunca visto.

Quando a aviação de longa distância se tornou lugar comum, foi dito que o mundo ficara menor, e as distâncias foram encurtadas. A partir do smartphone com acesso à internet, o mundo tornou-se uma aldeia e as distâncias deixaram de existir, no que tange à comunicação interpessoal e à transmissão de conhecimento que possa ser convertido à forma eletrônica.

\section{DESENVOLVIMENTO}

A comunicação digital portátil sofreu uma evolução vertiginosamente rápida. $O$ primeiro celular usando comunicação digital surgiu no início da década de 1990. A primeira mensagem de SMS foi enviada em 1993. $\mathrm{O}_{3} \mathrm{G}$ para comunicação digital via celular surgiu no início de 200I - acaba de completar suas duas primeiras décadas de existência!

Em 2009, o WhatsApp foi lançado, com uma espécie de substituto bastante aperfeiçoado das mensagens via SMS, já que transmitia arquivos de imagens, áudio e vídeo, entre outras capacidades inovadoras.

Seu uso como uma ferramenta de educação foi quase que imediatamente considerado, nem que fosse para estabelecer e manter a comunicação entre professores e pais de alunos.

É verdade que, não tendo sido criado para esse fim, o WhatsApp não apresenta facilidades específicas para a educação, e mesmo traz desvantagens em seu uso para esse objetivo. 
De imediato, podemos citar o fato de que o WhatsApp foi imaginado para uso pessoal e, para tal, é excelente. Não é à toa que dominou o mercado das mensagens instantâneas.

Por outro lado, exatamente por ser para uso pessoal, o aplicativo foi pensado para ser usado em apenas um aparelho, o que pode tornar o uso escolar difícil, especialmente para o professor, que terá um afluxo significantemente maior de mensagens (entre individuais e grupos) para o mesmo aplicativo configurado para seu uso pessoal.

Essa situação apenas se agrava no caso de professores que atuam em várias classes diferentes: não apenas eles tendem a ter um número muito maior de alunos, todos eles potencialmente enviando mensagens e esperando receber respostas do professor, como multiplicam-se os grupos de alunos e/ou classes ou ainda professores, e ainda é comum que os pais dos alunos também passem a trafegar mensagens regularmente. O professor precisa gerenciar um fluxo enorme de informações em um só celular, sem ter como separar as suas mensagens pessoais.

Do lado dos alunos e seus pais, a coisa não é muito melhor: um aluno pode ter que trocar mensagens com diversos professores, com seus colegas de sala, com o grupo da sala de que faz parte, com um possível grupo de professores. $O$ mesmo se aplica a seus pais, e se multiplica caso a família tenha mais de um filho.

Acrescente-se que qualquer dos usuários do WhatsApp (que, por já se aproximarem de dois bilhões, em todo o mundo, e terem no Brasil sua maior comunidade, provavelmente incluem todos os leitores desse artigo, e a esmagadora maioria das pessoas que os conhecem) sabe da dificuldade de se encontrar uma mensagem específica em meio a centenas de outras, de dias, semanas ou meses atrás.

Há uma série de outras "desvantagens" do WhatsApp como ferramenta de educação que, na verdade, são fruto do fato desse aplicativo não ser originalmente pensado como ferramenta de educação; é injusto cobrar-se dele ter facilidades típicas do trabalho escolar, como uma lista de chamada online, a distribuição de boletins virtuais ou a possibilidade de usar o WhatsApp para cobrança de taxas (o que parece ser um implemento pensado para o futuro do produto). 
É, no entanto, um fato conhecido de que o uso normal do WhatsApp para comunicação interpessoal já lota as memórias dos celulares com arquivos, nem sempre arquivos que precisem ser guardados, mas cujo armazenamento raramente passa por alguma ponderação antes de acontecer. O trabalho escolar, por definição, gera vastas quantidades de documentos que precisam ser arquivados, ao menos temporariamente, e o esgotamento constante da capacidade de memória dos aparelhos é uma possibilidade real, que pode causar grandes transtornos a todos os envolvidos.

Talvez o maior empecilho à ideia de utilizar o WhatsApp na área de educação é uma reclamação familiar a qualquer usuário do aplicativo, para seus fins previstos: o WhatsApp pode ser uma constante distração.

Mesmo em se considerando o uso, digamos, "sério" do aplicativo para fins educacionais, um professor (ou um aluno, ou um pai de aluno) receberá notificações constantes dos diversos grupos de trabalho de que faz parte.

Checando ou não estas notificações, isso já representará momentos em que sua mente se afastará do trabalho, o que certamente afeta a produtividade. Não as checar pode significar delegar a segundo plano situações que demandam ação urgente, imediata, e isso sempre tem resultados negativos. Por outro lado, checá-las no momento mesmo em que se apresentam é tirar o foco da tarefa em mãos, perder o fio da meada, como se diz, algo que tende a exigir tempo para ser recuperado.

E ainda não falamos daquilo que no WhatsApp representa real e constante distração; que é praticamente tudo que acontece quando o WhatsApp é usado para os fins para os quais foi inventado.

O professor que está lidando com cinco grupos de alunos e seus pais, mais pelo menos um grupo de professores da escola, e recebe notificações do grupo da família, que podem ser sérias ou podem ser uma simples piada. A mãe que passa situação perfeitamente familiar.

E o aluno, que é uma criança, para começar, e sempre vai achar mais interessante qualquer notificação de qualquer outro grupo, especialmente um grupo de amigos, e que será atraído irrevogavelmente para qualquer mensagem de um amigo, por mais irrelevante que ela pareça. 
E não esqueçamos que tudo isso estará acontecendo em um smartphone, com uma infinidade de outras ofertas, de jogos a vídeos a músicas a inúmeras e sortidas redes sociais a miríades de informações de interesse para pessoas daquelas idades - um conceito que não apenas tende a diferir grandemente do tipo de informações que interessa a adultos, como quase que com certeza afasta-se drasticamente do tipo de informações que se pretende sejam trabalhadas no ambiente escolar.

Esta prolongada lista de fatos atesta, sem sombra de dúvidas, a real impossibilidade de usar-se o WhatsApp para fins educacionais e, na verdade, sua condição nociva ao trabalho escolar. Estes fatos mostram que o próprio celular não tem lugar na sala de aula.

No entanto, essa interpretação está errada.

$\mathrm{O}$ ano de 2020 reconectou a humanidade com uma experiência que ela não vivia, em escala global, há pelo menos cem anos. A pandemia do COVID-I9 impiedosamente forçounos a mudar comportamentos de forma drástica; a escola foi apenas uma das esferas afetadas.

Em face do vasto impacto causado pelo vírus, não é difícil esquecer que a situação não estava exatamente um paraíso antes de sua trágica chegada, e que já demandava ações emergenciais, que raramente aconteciam. $\mathrm{Na}$ grande maioria dos casos, a pandemia instalou o caos em uma situação já catastrófica. E em não poucos casos, tudo ainda pôde ser agravado por tragédias posteriores.

O fim de 2019 encontrou o Líbano em meio à pior crise econômica desde a guerra civil de 1975-1990, o que causou poderosas manifestações populares contra a elite dominante (curiosamente, disparadas por uma proposta governamental de taxar mensagens de WhatsApp), que levaram à queda do primeiro-ministro, sem a imediata e óbvia ascensão de uma nova força política. O povo rejeitava qualquer facção que se apresentava. Bancos e escolas fecharam, estas últimas descartando qualquer plano de retorno às aulas naquele ano.

E aquilo foi 2019.

2020, como sabemos, não trouxe grandes melhorias ao quadro, nem no Líbano, nem no resto do mundo. As escolas, que tinham reaberto no início do ano letivo, tiveram que fechar com o lockdown. Em Beirute, os professores fizeram fotocópias de suas lições e deixaram-nas para os pais recolherem, pouco antes do anúncio do fechamento das escolas 
pelo resto do ano (nada da indecisão tensa que vimos por aqui, que passou 2020 ameaçando voltas descabidas às aulas, por motivos puramente políticos, descolados da ciência e da saúde).

Os professores libaneses não tinham ilusões quanto à penetração das aulas online: a crise econômica no Líbano não permitia que computadores pessoais e internet confiável chegassem sequer à classe média, quanto mais às classes socioeconômicas menos favorecidas.

Não ajudava a situação o fato de que a empresa governamental que administrava e ainda administra as telecomunicações no Líbano fosse marcadamente incompetente e / ou venal em seu trabalho. Como a área de telecomunicações é a que mais arrecada para o governo, não havia real interesse em investir nas melhorias e no desenvolvimento das estruturas. Como resultado, boa parte da rede de internet libanesa ainda é feita de fios de cobre, as velocidades de transferência são muito baixas e o serviço é caro. O libanês comumente frequenta cybercafés, onde ele consegue acessar a internet em velocidades melhores, uma realidade que o brasileiro não experimenta há mais de dez anos.

Ressalva importante: não é intenção deste artigo sugerir que a administração pública dos serviços de telecomunicações (ou de qualquer serviço de interesse público) é, por si, ineficiente, ou movida por desonestidade, e seria a causa do estado lamentável dos serviços de internet no Líbano. Até onde podemos observar, uma administração privada teria grandes chances de manifestar a preocupação com lucros que parece ter norteado a administração pública do Líbano, fazendo-a escolher não investir em custosas melhorias, que aumentariam a eficácia do serviço e reduziriam o custo. Por outro lado, uma administração pública verdadeiramente preocupada com o bem comum, não estaria preocupada com lucros, nem se comprometeria com eles, muito menos à custa da qualidade do serviço entregue ao consumidor final.

Perdoem-nos a digressão.

Enfim, face às evidentes dificuldades financeiras que impediam a maior parte $\mathrm{da}$ população de ter computador doméstico e internet de mínima qualidade, os professores 
compreenderam como as aulas online não eram fadadas ao sucesso, e dispuseram a procurar uma solução alternativa.

Uma solução logo se apresentou e, como não deve surpreender a nenhum dos leitores deste artigo, foi o WhatsApp.

Foi uma descoberta um tanto natural, que os professores fizeram enquanto se comunicavam através de seus grupos de WhatsApp, procurando uma forma de atender os alunos libaneses em meio à quarentena. Mesmo sem a solicitação da administração escolar, o WhatsApp tornou-se a solução informal de aprendizado à distância para professores e alunos.

Os educadores libaneses transmitem suas aulas utilizando mensagens de áudio ou vídeo, além de enviar vídeos e fotos, de forma a imitar a estrutura de uma sala de aula. Os resultados foram apreciáveis, ainda mais porque, enquanto algumas das plataformas mais avançadas para o ensino à distância exigem equipamento mais sofisticado, não disponível a todas as famílias, o WhatsApp, mesmo jamais tendo sido pensado como uma ferramenta de ensino, apresenta várias facilidades úteis, e pede apenas um smartphone com acesso à internet.

Por exemplo: em um grupo criado pelo professor, todos os textos e fotos aparecem como "vistos" assim que qualquer aluno acessa o grupo, como se simplesmente por ter entrado no grupo, aquele aluno tivesse instantaneamente lido todos os textos e observado todas as fotos. O que obviamente não é verdade, nem para aquele primeiro aluno, nem para os outros alunos da sala que, na prática, ficavam “invisíveis", já que sua entrada no grupo não aciona nenhuma espécie de sinal, e pode-se menos ainda saber se eles leram, de fato, alguma coisa.

Professores observaram, porém, que o WhatsApp tratava de modo diverso as mensagens de voz que eram enviadas ao grupo: cada aluno precisava verdadeiramente abrir cada arquivo de áudio para que aquele arquivo fosse indicado como "tocado". Desta forma, era possível postar mensagens de voz e verificar se alunos as tinham ou não ouvido, o que funcionava mesmo como uma espécie de lista de presença. 
Outra facilidade útil atende ao fato de que o Líbano oferece currículos escolares em francês e em inglês, embora os pais frequentemente só consigam falar fluentemente o árabe. As mensagens de voz, porém, permitem aos professores alternarem-se entre os idiomas.

Os professores libaneses logo perceberam que havia novos alunos em suas salas de aula: os pais dos alunos. Eram eles que exibiam os vídeos enviados para as crianças menores, filmavam seus filhos realizando as atividades $e$ os enviavam para validação e monitoramento por parte dos professores. Não era incomum que professores postassem no Facebook vídeos curtos do progresso de seus alunos, com comentários elogiosos e encorajadores aos pais, marcados em cada postagem.

Ainda assim, as condições econômicas que já assolavam o Líbano, associadas ao drama da pandemia, levaram ao fechamento de diversas escolas, com subsequente demissão de professores e diretores.

Foi quando, em 04/o8/2020, algo como 2.700 toneladas de nitrato de amônio (um fertilizante com tendências a tornar-se explosivamente instável, e que estava armazenado em um depósito no porto de Beirute desde que foi confiscado de um navio, em 2014) explodiram.

A explosão foi ouvida em Chipre, a 240 quilômetros de distância. Destroços foram vistos a mais de três quilômetros de distância, o que cobre uma área onde viviam 750.000 pessoas. O porto, que é a maior via de importações que sustenta o país, foi completamente destruído. Um silo, com 85 por cento dos grãos que alimentariam o país, foi destruído. Mais de 300.000 habitantes de Beirute (pelo menos um terço deles sendo crianças em idade escolar)

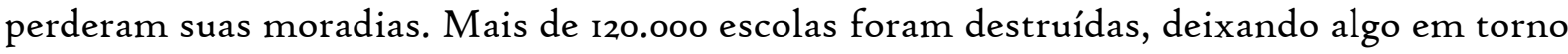
de 55.000 alunos sem salas de aula físicas. As autoridades libanesas planejam alojar as famílias sem teto nas escolas que resistiram à explosão. As chances de um retorno presencial às aulas são bem pequenas.

Isso torna a iniciativa das "escolas de WhatsApp" ainda mais importante. Psicólogos entendem que mesmo os efeitos psicológicos negativos de longo prazo causados pelo prolongado afastamento dos alunos da sala de aula podem ser amenizados pelo uso do 
WhatsApp, através da partilha de fotos e vídeos, que podem ajudar as crianças a reconectarem-se.

É gratificante perceber que, mesmo em circunstâncias ainda mais negativas e trágicas do que as que estamos vivendo, o WhatsApp, em especial, e a internet, de modo geral, ofereceram soluções viáveis na área educacional.

Debrucemo-nos agora sobre a situação que enfrentamos no Brasil de 2021, e vamos tentar analisar o cenário da escola com o envolvimento da internet, considerando as experiências realizadas e o que ainda pode ser tentado, e ainda quais as dificuldades específicas de nosso quadro sociopolítico.

Não deve existir quem discorde de que a disponibilização de informação correta, checada e atualizada (ou mesmo rapidamente verificável), no exato momento em que ela se faz necessária, torna a vida uma experiência diferente (e muito melhor) do que a maioria de nós, adultos, já viveu. Não é preciso puxar pela memória para recordar situações em que escolher um restaurante exigia consultar várias fontes impressas (por definição, desatualizadas), talvez algumas ligações telefônicas a números possivelmente já inválidos e, mesmo assim, correr o risco de chegar ao estabelecimento e descobrir que os preços haviam mudado ou, em casos extremos, o restaurante nem estava mais ali.

Nós, professores, temos um pesadelo mais particular e próprio. Tudo o que desejamos é um aluno interessado e curioso - exceto, claro, quando ele nos pergunta a capital do Sudão do Sul, o que é um dado que não virá facilmente à ponta da língua de muitos.

Em outros tempos, esse dado (que mais se tornaria imprescindível na medida que se esquivasse à captura) precisaria ser demoradamente buscado em fontes, como os livros escolares mais à mão, que possivelmente não o trariam; e acabar-se-ia (após tempo considerável) recorrendo à boa memória de alguém interessado no tema, que talvez sugerisse Ulam Bator, ou Nursultan, sem um grau confortável de certeza.

Hoje, o leitor pode já ter usado seu celular para encontrar a resposta certa no tempo que usaria para ler o parágrafo acima: a capital do Sudão do Sul é Juba, e a razão por que essa informação talvez não seja facilmente encontrada em um livro escolar de geografia, ou em um volume impresso de enciclopédia, é que o Sudão do Sul é o país mais novo do mundo, 
tendo alcançado sua independência através de um referendo em janeiro de 20Ir. Não é descabido imaginar-se que ainda haja livros, em 2021, que não reflitam essa mudança recente. Vale ressaltar que, a despeito de sua louvável boa vontade, o colega interessado também teria errado, já que Ulam Bator é a capital da Mongólia, e Nursultan é a capital do Cazaquistão.

E se o leitor tiver, de fato, conseguido descobrir qual é a capital do Sudão do Sul mais rápido do que o tempo de leitura de um parágrafo, isso terá sido pelo uso de seu celular com acesso à internet.

Transportando a cena de volta à sala de aula, mas nas condições atuais, a pergunta incômoda não seria sequer incômoda: a internet nos proporcionaria a informação imediatamente, correta, atualizada, verificada. Enriqueceria a aula não apenas por responder a curiosidade do aluno interessado, o que é sempre benéfico, mas por abrir possibilidades imprevisíveis de ensino, de distribuição e produção de conhecimento: o professor poderia rapidamente discutir essa situação incomum de um país mais novo do que a maioria dos alunos, tratar da trágica e vergonhosa circunstância histórica que fez os atuais países africanos surgirem de longas batalhas por independência de países europeus majoritariamente brancos, que mais os exploraram econômica e socialmente do que se preocuparam em cuidar e desenvolver os povos nativos, fazer um comparativo com nossa própria História colonial.

E esse é apenas um exemplo escolhido, e extremamente específico, que pode enriquecer enormemente uma aula. A internet já proporciona gratuitamente artigos de texto confiáveis, ilustrados por imagens fiéis, e vídeos de alta qualidade sobre praticamente todos os assuntos que podem ser levantados em uma sala de aula. Mais difícil para o professor será escolher do leque variadíssimo de opções, e enviar links para seus alunos, através do WhatsApp, que foi o astro desse artigo até aqui. Arquivos de voz ou de texto produzidos pelo professor completariam o trabalho pedagógico, exercícios especialmente preparados (ou escolhidos em meio à oferta disponível) testariam o aprendizado.

A internet não se limita a oferecer produtos prontos: há inúmeras ferramentas disponíveis para que professores e alunos filmem e editem seus próprios vídeos, adicionem seus próprios efeitos especiais, criem e editem seus próprios podcasts, suas próprias 
animações, a partir de seus próprios desenhos, ou não. Estas ferramentas são quase sempre simples e gratuitas; mas se não o forem, há alternativas gratuitas e mais simples, e há tutoriais que ensinam gratuitamente como usar as ferramentas que existem. E todos estes trabalhos podem ser compartilhados pelos professores com os alunos, seja individualmente, seja em grupo, por WhatsApp, a custo zero.

A internet está aí há bastante tempo; nós é que não tínhamos prestado a devida atenção. A quarentena fez-nos a todos descobrir possibilidades tecnológicas que vínhamos nos recusando a experimentar, como os softwares que permitem reuniões em tempo real, mesmo que cada participante esteja em locais remotos e distantes entre si. É improvável que muitas reuniões presenciais de trabalho continuem a acontecer, mesmo quando a pandemia permitir.

As possibilidades são estonteantes. O céu é o limite.

Há limites, porém, e eles vêm de fora da esfera eletrônica, direto do mundo físico.

O estudo do caso do Líbano mostrou-nos como uma sociedade economicamente frágil e desigual, politicamente instável e socialmente abalada lida com dificuldades que sequer existem em nações mais favorecidas. O Brasil de 202I não sofreu uma explosão com as proporções de um terremoto, e tem melhores condições socioeconômicas básicas; mas nosso país não está tão melhor assim do que o Líbano.

Como dissemos acima, o Whats App demanda pouco mais do que um smartphone com acesso à internet; mas o uso das possibilidades mais amplas da internet que também citamos pede equipamentos fisicamente disponíveis e/ou instalados, e o avanço da tecnologia exige a atualização quase constante desses equipamentos, o que redunda em custos financeiros raramente baixos. Não precisamos enfatizar que a porção mais pobre de uma sociedade dificilmente terá acesso a todas as possibilidades da internet; e que, para aqueles que têm dificuldades até em alimentar-se regularmente, adquirir um celular minimamente capacitado e pagar mensalmente pelo acesso à internet pode ser algo próximo de um sonho irrealizável.

Em nossa sociedade, e na esfera educacional, temos duas realidades bastante distintas: a educação pública e a educação privada. 
A realidade das escolas particulares, e as condições socioeconômicas de sua clientela, serão o ambiente mais fértil para que viceje a parceria entre ensino e tecnologia. É evidente que uma ferramenta absolutamente comum, espalhada e gratuita como o WhatsApp será usada em todas as suas capacidades, com grupos sendo criados para cada sala de aula, ou mesmo para grupos pequenos de trabalho na turma, materiais de estudo sendo facilmente distribuídos, inclusive adaptados às necessidades de cada aluno ou grupo de alunos, etc.; e as chances de todos os alunos e seus pais terem smartphones de qualidade, com acesso rápido e estável à internet são bem grandes.

Os outros recursos de internet que mencionamos, porém, aqueles que demandam ou são mais bem aproveitados com equipamentos de alta performance, e que devem ser mantidos atualizados, com todos os custos envolvidos nessa manutenção, esses terão melhor utilização na escola particular, que mais facilmente terá acesso aos recursos financeiros necessários, e que provavelmente fará propaganda de suas iniciativas tecnológicas para atrair mais clientes pagantes.

$\mathrm{Na}$ escola particular, mais facilmente haverá a produção de vídeos, por alunos e professores, com celulares melhores, com edições e efeitos mais sofisticados, mesmo que isso exija cursos especiais de treinamento, para alunos e professores, que serão mais facilmente oferecidos e pagos. $\mathrm{Na}$ escola particular, equipamentos como lousas digitais serão mais facilmente encontrados, e computadores mais modernos acessarão softwares mais avançados. Enfim, cremos já ter deixado clara a situação: o céu é o limite.

Lamentavelmente, com as escolas públicas, o limite está mais próximo do solo.

Classicamente, a escola pública padece de uma falta de recursos crônica, o que é mais grave, já que a população que ela atende, por definição, não possui recursos, e depende de um aporte regular de recursos públicos.

Com a pandemia, o habitual descaso público com a educação teve que ser contido; foram planejadas aulas online, foram fornecidos computadores aos professores, foram fornecidos chips aos alunos para que acessassem a internet gratuitamente, entre outras medidas tomadas por cada região. 


\section{CONCLUSÃO}

A pandemia também ressaltou a já citada desigualdade social: ainda que tivessem recebido chips para acessar a internet, não são poucas as famílias que não possuem o computador ou o celular para isso, ou a família possui apenas um celular, que muitas vezes fica com o pai ou a mãe durante todo o dia de trabalho. As aulas online planejadas, como dito acima, aconteceriam em um horário definido do dia letivo, o professor e todos os alunos online ao mesmo tempo; se uma parte significante dos alunos não tem acesso ao celular, isso torna as aulas online pouco praticáveis.

E mesmo que sejam criadas formas alternativas de levar a matéria ao aluno - usando uma das plataformas de ensino existentes, por exemplo - que não exijam que a criança tenha acesso a um celular ou computador em um horário fixo do dia, pode ser que esse equipamento só esteja disponível tarde da noite, quando o pai ou mãe chegam do trabalho, ou somente no fim de semana. E ainda há o caso nada incomum de famílias com mais de uma criança em fase escolar, mas somente um celular...

E não devemos nos esquecer de que crianças são crianças, não personagens fictícios e ideais; nem sempre, e nem toda criança vai acordar de manhã ávida para aprender; ainda mais em um ambiente de pandemia, que as deixou longe de aulas regulares e presenciais por mais de um ano; ainda mais em um sistema educacional público que é historicamente mal financiado, mal estimulado, mal provido, e que torna ainda mais difícil criar gerações de alunos mais interessados no estudo, se eles já não o forem naturalmente.

Não se trata aqui de culpar as crianças se elas demonstrarem um desinteresse pelos estudos, que pode, em tese, redundar em um suposto insucesso futuro; como foi dito acima, o papel delas é o de vítimas de políticas educacionais públicas questionáveis (para dizer o mínimo), que vêm se perpetuando por décadas. Poder-se-ia pensar que haveria um desinteresse extraoficial em que a educação pública dê certo, sob pena de ter-se que lidar com uma classe trabalhadora educada, preparada e questionadora e, como tal, muito mais difícil de manipular e alijar de seus direitos.

Impressões fictícias à parte, o que sustentamos é que os alunos da escola pública já têm muito o que enfrentar para aprender; e o de que eles não precisam é ter todo um cenário 
que os desestimule ainda mais. Especialmente quando, na escola particular, a situação é tão diversa que parece estar acontecendo em outro planeta, ou outro tempo. Não se pode esperar que alunos de uma escola e de outra atinjam resultados minimamente similares.

A internet, em geral, e o WhatsApp, especificamente, podem operar milagres na educação, quer estejamos enfrentando uma pandemia, quer estejamos nos "tempos normais”, que ainda nem sabemos como serão. É bem verdade que a educação no Brasil precisa, de fato, de um milagre.

Os recursos estão disponíveis, mas eles dependem de algo mais do que boa vontade e estratégias de marketing. É preciso real vontade política.

Abrimos esse artigo falando que as evoluções da tecnologia e da humanidade andaram juntas por quase toda a História, até o século XX, quando a tecnologia avançou de tal modo que superou em muito as capacidades humanas. Terminamos esse artigo concluindo que há mais empecilhos à evolução da humanidade, que não a simples impossibilidade de o ser humano dobrar suas capacidades a cada dois anos, como fazem os computadores. Parte da humanidade tampouco consegue ter suas capacidades equiparadas às de outra parte, e isso não é causado pela tecnologia.

\section{REFERÊNCIAS}

ALONSO, Luiza Beth Nunes; FERNEDA, Edilson; SANTANA, Gislaine Pereira. Inclusão Digital e Inclusão Social: contribuições teóricas e metodológicas. Revista Barbarói, Santa Cruz do Sul, Artigo, n. 32, jan./jul., 2010. Disponível em: 〈http://pepsic.bvsalud.org/pdf/barbaroi/n32/n32aio.pdf〉 Acesso: 20 jul. 2021.

BERTOTTI, Mauro. Explosão em Beirute: quando a negligência se transforma em tragédia. Jornal da USP, Artigo, 2020. Disponível em: <https://jornal.usp.br/artigos/explosao-embeirute-quando-a-negligencia-se-transforma-em-tragedia/> Acesso: 20 jul. 2021.

CARVALHO JÚNIOR, Ciro Ferreira de; ARRAIS, Ciro Matheus Coelho; CARVALHO, Kely Rejane Souza dos Anjos de; RIBEIRO, Antônio Júnior Moraes. A Evolução da Internet: uma visão geral. Instituto Federal do Tocantins, Jornada de Iniciação Científica e Extensão, Artigo, 2017. Disponível em: $\langle$ https://propi.ifto.edu.br/ocs/index.php/jice/8jice/paper/viewFile/8269/3788> Acesso: 20 jul. 2021.

COUTINHO, Gustavo Leuzinger. A Era dos Smartphones: um estudo exploratório sobre o uso dos smartphones no Brasil. 67 f. 2014. Universidade de Brasília, Monografia. 
Disponível

em:

〈https://bdm.unb.br/bitstream/ro483/9405/r/2014_GustavoLeuzingerCoutinho.pdf〉 Acesso: 20 jul. 2021.

FELICIANO, Léia A. dos Santos. O uso do WhatsApp como ferramenta pedagógica. XVIII Encontro Nacional de Geógrafos, Anais, 2016. Disponível em: <http://www.eng2016.agb.org.br/resources/anais/7/1467587766_ARQUIVO_ArtigoAGB. pdf> Acesso: 20 jul. 2021.

HABIB, Sérgio. Os cedros do Líbano sangram! Revista Direito UNIFACS, Artigo, n. 245, 2020. Disponível em: 〈https://revistas.unifacs.br/index.php/redu/article/view/6952/422I > Acesso: 20 jul. 2021.

HAYNE, Luiz Augusto; WYSE, Angela Terezinha de Souza. Análise da evolução da tecnologia: uma contribuição para o ensino da ciência e tecnologia. Revista Brasileira de Ciência e Tecnologia, Artigo, v. II, n. 3, p. 37-64, set./dez., 2018. Disponível em: $\langle$ https://periodicos.utfpr.edu.br/rbect/article/download/5947/pdf > Acesso: 20 jul. 2021.

PAULINO, Danilo Borges; MARTINS, Caio Cabral de Araújo; RAIMONDI, Gustavo Antônio; HATTORI, Wallisen Tadashi. WhatsApp como recurso para a Educação em Saúde: contextualizando teoria e prática em um novo cenário de ensino-aprendizagem. Revista Brasileira de Educação Médica, Artigo, v. 42, n. I, p. I71-18o, 2018. Disponível em: <https://www.scielo.br/j/rbem/a/zpMrfKm3JS8kKQXV43WwS 7p/?format=pdf\&lang= pt> Acesso: 20 jul. 2021.

PORTO, Cristiane; OLIVEIRA, Kaio Eduardo; CHAGAS, Alexandre. Org. WhatsApp e Educação. Salvador: EDUFBA; EDITUS, 2017. Disponível em: $\langle$ http://books.scielo.org/id/r3xgc/pdf/porto-9788523220204.pdf〉 Acesso: 20 jul. 2021.

MENDONÇA, Vinícius Rafael Lobo de; BITTAR, Thiago Jabur; DIAS, Márcio de Souza. Um estudo dos Sistemas Operacionais Android e iOS para o desenvolvimento de aplicativos. XV Encontro Anual de Computação, Anais, 20Ir. Disponível em: <https://www.enacomp.com.br/20II/anais/trabalhosaprovados/pdf/enacomp2oII_submission_54.pdf> Acesso: 20 jul. 2021.

SIMPLICIO, S.S.; SANTOS, V.L.A.; CAMPOS, W.R.A; GUIMARÃES, D.G.; GONSALVES, A.A.; ARAÚJO, C.R.M. Nitrato de Amônio: mocinho ou vilão? Revista Virtual de Química, Artigo, v. I3, n. I, p. 156-166, 2021. Disponível em: $\langle$ http://static.sites.sbq.org.br/rvq.sbq.org.br/pdf/vizniaiı.pdf $\rangle$ Acesso: 20 jul. 2021.

STIVAL, Hudson P.; CARLOS, Luiz; ALMEIDA, Tatiane M. A. L. O processo da evolução tecnológica. Semana Acadêmica Revista Científica, Artigo, 2013. Disponível em: 〈https://semanaacademica.com.br/system/files/artigos/artigo_5_o.pdf〉 Acesso: 20 jul. 2021. 